\title{
Public Assets Management: Would Mutual Cooperation with other Actors in Forest and Wildlife Sectors Really Help?
}

\author{
Dr. Wenceslaus Mselya Sobayi \\ Faculty of Arts and Social Sciences, University of Nottingham, Malaysia Campus
}

\begin{abstract}
The Government of Tanzania decided to cooperate with other actors particularly local communities in improving forest and wildlife management by approving Forest Policy 1998 and Wildlife Policy 2007 (RE). The decision to entrust local communities with control over forest and wildlife reserves can help in plummeting many of the ills such as human-wildlife conflicts, deforestation and poaching. However, giving managerial responsibilities to local communities without looking after their livelihood is something that need to be reconsidered. When JFM and WMA models were introduced, the expectation was the same would bring about an improved cooperation and livelihood of local population. The two models have been brought into Tanzania by development partners as part of the technical and financial support in managing forest and wildlife resources. Thus, these models neither originated from the local communities nor have their development priorities been considered, and that explains why livelihood outcomes of local communities have been poor. The paper suggests that MNRT and development partners should know that local communities have different expectations of improving their livelihood outcomes. The paper also suggests that MNRT should ensure that local communities are at the centre of any development support program, and they (i.e. local communities) should be the ones determining development priorities and influencing the institutions involved in the processes that affect their lives. The paper further suggests that any kind of future intervention must recognise, appreciate and respect the differences that exists among actors involved in forest and wildlife management such as overall well-being, gender, age, ethnicity, level of education etc. The MNRT should look at local communities as organisations which possess required knowledge and skills to manage their local forest and wildlife resources. MNRT should ensure that when livelihoods analysis is conducted, emphasis is placed on how people earn their living. MNRT should also ensure that there is a frequent reviews of the practices used to deal with various livelihood and vulnerability issues during implementation of a particular support program in forest and wildlife management. These reviews must be conducted on both sides (of MNRT and development partners on one hand as well as local communities involved on the other), in response to various changes particularly on vulnerability context that usually take place in an effort to avoid unintended consequences. Keywords: Local Communities' Participation, Livelihood Outcomes, Forest and Wildlife Management, Tanzania DOI: $10.7176 / \mathrm{DCS} / 10-5-07$
\end{abstract}

Publication date:May $31^{\text {st }} 2020$

\section{Introduction}

The Government of Tanzania implemented its first post-independence Forest Act No. 14 of 2002 as a new legislation to replace the colonial legislation, known as Forest Ordinance Cap. 389 of 1957 (Nelson et al 2007). For over forty years, the Forest Ordinance Cap. 389 of 1957 was used to govern forest operations and safeguard forests in Tanzania, however, it lacked involvement of other actors particularly local communities and caused widespread invasion of the forests (UNEP 2002).

Historically, for the past five decades, local people have been excluded from engaging in processes relating to forest which could provide mutual benefit for the Government and local communities in Tanzania (UNEP 2002). This systemic marginalisation is responsible for the continued deterioration, deforestation and degradation of forests and the resources therein (Lokina and Robinson 2008). Nonetheless, several reforms such as introduction and implementation of Forest Policy 1998, have not improved the livelihood outcomes of local communities living near the forests (Hamza and Kimwer 2007). Through Forest Policy 1998, the Government of Tanzania is in pursuit of dual objectives of arresting forest degradation and furthering development (MNRT 1998a). The Government intends to achieve this by officially supporting devolution of ownership and management responsibilities of forest resources to local communities by using Community Based Forest Management (CBFM) and Joint Forest Management (JFM) models of Participatory Forest Management (PFM) program (MNRT 1998a; Wily and Dewees 2001).

The CBFM model does concern with devolution of ownership and management responsibilities of forest resources to local communities and leads to legal establishment of village land forest reserves, while the second model of JFM is used in government forest reserves, where managerial responsibilities are shared between local communities and the central government while the later retain ownership (Blomley and Ball 2010). The minimal participation of local communities in forest management is largely due to the historical domination of the central government in managing forest resources under the socialist economy governed by the Arusha declaration in which everything was controlled centrally at the top (Maganga 1993). 
In other respects, the existing Wildlife Policy 2007 (RE) is a revised edition of Wildlife Policy 1998, which attempted to initiate the devolution of wildlife operations to local communities (MNRT 2007). Wildlife Policy 2007 (RE) is legally supported by the current Wildlife Conservation Act No. 5 of 2009 which repealed and replaced the Wildlife Conservation Act No. 12 of 1974 (Laltaika 2014).

The Wildlife Policy 1998 was initially introduced during the era of Wildlife Conservation Act No. 12 of 1974 (Nelson et al 2007). Its main focus was to devolve wildlife operations to local communities, in order to achieve this, Wildlife Management Area (WMA) model was introduced and its regulations was prepared and issued in 2002 (MNRT 1998c; 2003). The very idea of WMA model is devolution of power and authority in managing wildlife resources. WMA is an area declared by the minister to be so and set aside by village governments for the purpose of biological natural resource conservation" (MNRT 1998b p.34). However, Wildlife Policy 1998 somehow continues to maintain state ownership and control of wildlife resources (Shauri 1999).

State trusteeship is indeed a fundamental cause of land and natural resource conflicts that have intensified in recent years within and around protected areas in Tanzania (Neumann 1992; Homewood and Rodgers 1991; Potkanski 1997). The Wildlife Policy 1998 has introduced some positive concepts such as: a call for better management of the protected estate, sustainable use of wildlife resources, devolution of wildlife user rights to local communities and sharing of benefits derived from wildlife use and resources through establishment of WMAs (MNRT 1998b). However, procedures to establish a particular WMA or obtain licenses and easements are lengthy and lead to unnecessary delays and bureaucratic red tape which defeat the purpose of establishing WMAs and the overall idea of devolution of power and authority in managing wildlife resources (Shauri 1999).

In implementing WMA model in Tanzania, local communities including village government officials, claim that they have been brought into the WMA without their knowledge or consent (Igoe and Croucher 2007). In Tanzania the WMAs are not designed in ways that allow the villagers to make informed decisions about this process (Goldman 2003). Although Wildlife Policy 1998 envisages that WMAs will ensure that local communities will have full mandate of managing and benefiting from their conservation efforts (MNRT 1998b), legal ownership and control of wildlife resources remains with the state (Igoe and Croucher 2007).

While WMA model demands involvement of members of a particular local community and informed consent, yet the highly technical and legalistic nature of WMAs makes it possible to create one without their consent (Cernea and Schmidt-Soltau 2006). Based on the premise established above, the research question is posed: how has change in local communities' involvement in managerial process, affected their livelihood outcomes and whether or not they lead to changes that are conducive to improve forest and wildlife management in Tanzania?

\subsection{Study objective}

To examine the way change in local communities' involvement in managerial process has affected their livelihood outcomes and whether or not they lead to changes that are conducive to improve forest and wildlife management in Tanzania.

\subsection{Research models}

The theoretical framework which underpinning this research lies with the DFID livelihoods model and Ostrom model of Institutional Analysis and Development (IAD). The DFID livelihoods model states that, a particular livelihood outcome is affected by three variables namely, vulnerability context, structures and processes (GLOPP 2008 p.2).

The DFID livelihoods model works by ensuing some of the underlying assumptions that: households are at the centre of any development program or project and should be the ones determining development priorities and be able to influence the institutions involved as well as the processes that affect their lives; and households should use their asset base to develop a range of livelihood programs or projects which would enable them to achieve their desired livelihood outcomes (GLOPP 2008 p.1).

Meanwhile, the model works by following some of the underlying principles that: livelihoods analysis must be holistic in terms of identifying both internal and external factors which have positive or negative impact on livelihoods of particular households and also ensure participation of members of households; and the livelihoods analysis when conducted must be based on how people make their living (GLOPP 2008 p.1).

The IAD model developed by Elinor Ostrom, suggests that communities can contribute enormously in reducing the policy gap, once they have been entrusted to manage resources without government intervention. The model challenged the conventional wisdom about the need for government intervention over management of public resources in order to attain sustainability and benefit sharing (Ostrom 2005 p. 219).

The IAD model works by following some of the underlying assumptions that: institutions are being considered as man-made systems within which individual choices are allowed to take place in order to achieve a particular outcome; interaction and mutual trust is necessary in any established social system; and actors within a system can choose for themselves what type of outcome they wish to achieve (Ostrom 2005 pp.50-55).

Meanwhile, IAD model works by following some of the underlying principles that: interactions among actors 
must be guided by a set of rules in order to achieve an outcome; there must be rewards or punishments in order to achieve an outcome; and each actor must be assigned a particular position, in other words, each must have a role to play in order to achieve the outcome (Ostrom 2005 pp.193-207).

\subsection{Narratology of the Study}

A qualitative approach was found to be more appropriate in understanding how has change in local communities' involvement in managerial process, affected their livelihood outcomes and whether or not they lead to changes that are conducive to improve forest and wildlife management in Tanzania? The preference given to qualitative approach over quantitative in this study was due to the fact that, quantification of policy effects in Tanzania has been difficult because of lack of reliable, consistent and comprehensive data in almost all sources of statistics (UNEP 2002).

In this study, interpretivism was chosen as the research philosophy. Additionally, a flexible research design was adopted and an interpretive case study was employed. Since the study was qualitative, semi-structured interviews and interactions were conducted. In establishing the sample size and choosing respondents and sampling technique, the sample size was 40 respondents and non-probability sampling technique was chosen, and technique used was purposive.

Data transcription was carried out by professional transcribers and later translated from Swahili to English by independent translators to ensure limited chance of subjectivity and bias in the study. Data transcribed and translated were subsequently entered into NVivo software where they were auto-coded and analysed until themes were identified. After these themes were identified, each theme was further analysed and interpreted by using analytical techniques of Content analysis and Narrative analysis.

The logic behind data interpretation in narrative analysis is to translate the stories of respondent's experiences into a narrative form. Narrative form is said to be produced, once a coherent story from data has been constructed. In short, through the use of narrative analysis, the author provides new and interpreted narrative which has a different message, embedded with unbiased personal opinion when being constructed (Segel and Heer 2010).

\section{Local Communities' Participation and Effects on their Livelihood Outcomes}

Traditionally, local communities countrywide have been using forests and wildlife resources to support their livelihood. The local communities depend on forests for energy which comes from fuelwood (and sometimes charcoal), for building their houses using wooden poles, for pasturing their cattle on the grass, for concocting traditional medicines from wild herbs and for worshiping nature and idols.

However, study shows that, there is a decrease in livelihood of local population and subsequently causes an increase in forest degradation and deforestation. The study shows that when PFM was introduced, there were two main objectives. Firstly, to improve forest condition; and secondly to improve livelihood. Nonetheless, implementation of PFM has neither succeeded in improving forests condition nor livelihood of local population. In other words, PFM has not been able to achieve its intended objectives.

The fact that PFM neither contribute to the improvement of forest condition nor livelihood of local communities, indeed poses grave concern to all actors involved in forest management. In comparison, failure of PFM to improve livelihood is mostly seen in areas where JFM model is used, and not in other areas that employ the CBFM model. Study shows that CBFM model improves both condition of forest reserves and livelihood of local population, although, the model is used in only few forest reserves. The CBFM model increases involvement of local communities in managing forest resources due to the transfer of ownership of the forest land from central government to village government. JFM model has proven to be successful in improving the condition of forests only and not livelihood of local population. The JFM model is widely used by MNRT in managing most of the forests in Tanzania.

A case in point, is Monduli forest reserve, a joint forest reserve which uses the JFM model to specifically preserve and protect sources of water in Monduli district area. Monduli forest reserve is a catchment forest reserve located in Monduli district whereby productive activities such as logging are prohibited. The Monduli forest reserve is also surrounded by wildlife reserves which harbour many animals that tend to migrate into the forest reserve in search of food and water. Eventually, by having many animals residing in the reserve, residents in local communities are inclined to hunt animals and also to fetch water for their domestic use.

The Monduli forest reserve has a unique tree known as "Junipera Spocera" used by the Maasai tribe for building houses. Hence, under such circumstances, MNRT's decision to use JFM model in Monduli forest reserve instead of the CBFM model, has made that particular forest reserve vulnerable to encroachment and other activities which adversely affect the Monduli forest reserve, due to the fact that local communities heavily depend on that particular forest reserve to improve their livelihood. JFM model is also used in some areas such as Handeni Hill, Gologolo and Kipumbwi forest reserves located in Tanga as well as Udzungwa forest reserve in Iringa region.

Therefore, in order for PFM to contribute to local communities' livelihood, there should be a mutual trust between bureaucrats and local communities. The bureaucrats should entrust local communities with the full control 
of forest reserves. Improved livelihood will definitely lead into better forest management. The study shows that local communities' encroachment into forests is primarily for the pursuit of daily human needs and establishment of settlements as nowadays habitable land space is limited. Unfortunately, MNRT sees local communities as drivers of many ills that take place in forest reserves. Eventually, MNRT has chosen to implement JFM model as an alternative for alleviating problems that prevail in forest management.

Study shows that mutual cooperation between MNRT and local communities is vital for improving livelihood of local population. However, application of JFM model does not help to foster the needed cooperation between MNRT and local communities as in many cases, MNRT prefers to make decisions and expecting local communities to be implementers.

The study further indicates that application of JFM model lengthened the time taken in making decisions and eventually affects local communities in planning and use forest resources as their asset base to develop livelihood projects which would enable them to achieve their desired livelihood outcomes. Thus, giving management responsibilities to local communities without looking after their livelihood is something that need to be reconsidered. The decision to entrust local communities with control over forest reserves can assist in reducing the problem of inadequate manpower that exists in forest management countrywide.

In other respects, study shows that in order to improve livelihood of local communities, WMA model should be properly implemented by allowing them to make decisions on matters of wildlife management. Local communities must be allowed to collect revenue from consumptive and non-consumptive activities such as hunting, trapping, fishing, wildlife viewing, photographing and other income generating wildlife management activities. However, during implementation of WMA model, MNRT usually collects revenue and does not timely disburse back the amount collected from WMAs as required by the Twelfth Schedule of WMAs Regulations 2012, and even when the amount is paid to local communities, it is always less than the required amount and its computation is not transparent.

A case in point, is Burunge WMA which is situated between Tarangire and Lake Manyara national parks. It receives minimal funds to support wildlife operations compared to the steady increase in the amount of revenue generated by this particular WMA. Additionally, there is another example of Enduimet WMA which is located between Kilimanjaro national park and Amboseli national park of Kenya, which receives minimal funds as compared to the amount of revenue generated there. This particular WMA is primarily an elephant corridor.

As leading beneficiaries, local communities expect to be more involved in making decisions on matters of wildlife operations within WMAs. In so doing, it would indicate that WMA model has really taken wildlife management down to lowest level of local communities. On the contrary, the Wildlife Management Areas Regulations 2012 has continued to empower the Director of Wildlife (DW) at MNRT (i.e. by centralising the power and authority) who has absolute control over managing wildlife resources within WMAs. The DW can decide whether to approve or disapprove any investment decision especially in hunting business which is the main source of revenue in WMAs.

On the other hand, some wildlife management authorities such as Tanzania National Parks Authority (TANAPA) has decided to develop social projects within local communities as a way of alleviating the effects of incurred losses and tension that local communities usually experience from Human-Wildlife Conflicts (HWCs). The social projects include building schools, dispensaries and wells. Alternatively, in order to improve livelihood, TANAPA and MNRT could put more effort into establishing economic projects rather than investing in social projects. Doing so would pave way for the creation of many hired and self-employment opportunities. The decision to introduce social projects into local communities has minimal impact in improving livelihood and alleviating HWCs.

Furthermore, MNRT has continued to control hunting block allocations within WMAs. Study indicates that hunting block allocations are subject to renewal or cancellation at the discretion of DW in MNRT regardless of any contractual agreement which local communities may have (with the hunting company). In other words, local communities cannot make own decisions on matters relating to wildlife management within WMAs which subsequently affect their livelihood.

The WMAs Regulations 2012 recognises DW in MNRT as the countrywide manager of WMAs and not the local communities. In that case, the way MNRT is managing WMAs, goes contrary to the principles of the WMA model which is to take ownership and control of the wildlife resources down to local communities with the aim of improving their livelihood. Hence, lack of ownership and control in managing WMAs has prevented local communities' from getting involved in daily management of wildlife resources which in turn, has adversely affected their livelihood.

\section{Better cooperation for better livelihood outcomes}

The JFM and WMA models have been brought into Tanzania by development partners (i.e. NORAD) as part of the technical and financial support in forest and wildlife management respectively. Study suggests that MNRT should ensure that local communities are at the centre of any development support, and they (i.e. local communities) 
should be the ones determining development priorities and influencing the institutions involved in the processes that affect their lives.

MNRT should not see local communities as drivers of the problems that exists in forest and wildlife management, and also local communities should stop complaining that, they are being denied of their right to make use of forest and wildlife resources for improving livelihood outcomes. The inclusion of local communities in determining development priorities is critical.

By bringing in models such as JFM and WMA which have neither originated from the local communities nor have their development priorities been considered, it explains why livelihood outcomes have been poor. It is obvious that when JFM and WMA models were introduced by development partners in the first place, its main objective was not to improve the livelihoods of local communities but rather to have better forest and wildlife conservation. Thus, MNRT and development partners should know that local communities have different expectations of improving their livelihood outcomes.

Moreover, study suggests that any kind of future intervention must recognise, appreciate and respect the differences that exists among the actors involved in forest and wildlife management such as overall well-being, gender, age, ethnicity, level of education etc. MNRT should look at local communities as organisations which possess required knowledge and skills to manage their local forest and wildlife resources. Unfortunately, during implementation of JFM and WMA models, MNRT and development partners regard local communities as drivers of deforestation, forest degradation, poaching and other ills in forest and wildlife management.

MNRT should also ensure that livelihoods analysis is conducted and most importantly, consideration should have been made on how people earn their living. MNRT should ensure that there is a frequent reviews of the practices used to deal with various livelihood and vulnerability issues during implementation of a particular support program in forest and wildlife management.

These reviews must be conducted on both sides (of MNRT and development partners on one hand, as well as local communities involved on the other), in response to various changes particularly on vulnerability context that usually take place in an effort to avoid unintended consequences. The study shows that there has been no systematically periodic reviews conducted on the practices involved in forest and wildlife management. For example, since 1998 when both forest and wildlife policies were introduced for the first time in history of forest and wildlife conservation in Tanzania, only the wildlife policy was revised in 2007. Both policies introduced and advocated the participatory approach in managing forest and wildlife resources by involving other actors particularly local communities and the private sector.

Additionally, the first WMAs regulations were introduced in 2002, four years after the Wildlife Policy 1998 was approved. The WMAs Regulations 2002 was later revised in 2012, ten years afterwards which shows there is no consistency as to when the reviews or reflections on practices that take place in addressing various livelihood and vulnerability issues. Meanwhile, forest policy has not been revised since 1998, and it is only now that there is an on-going review process.

\section{Conclusion}

This paper has examined the way change in local communities' involvement in managerial process, has affected their livelihood outcomes and whether or not they lead to changes that are conducive to improve forest and wildlife management in Tanzania. It is revealed that decision to entrust local communities with control over forest and wildlife reserves can help in plummeting many of the ills such as human-wildlife conflicts, deforestation and poaching. However, giving managerial responsibilities to local communities without looking after their livelihood is something that need to be reconsidered.

When JFM and WMA models were introduced, the expectation was the same would bring about an improved cooperation and livelihood amongst actors particularly the local communities, involved in forest and wildlife management. These two models have been brought into Tanzania by development partners through NORAD, as part of the technical and financial support in managing forest and wildlife resources. Thus, these models neither originated from the local communities nor have their development priorities been considered, and that explains why livelihood outcomes of local communities have been poor.

It is obvious that when JFM and WMA models were introduced by development partners in the first place, both had the main objective of better forest and wildlife conservation respectively, and not to improve the livelihoods of local communities. The paper suggests that MNRT and development partners should know that local communities have different expectations of improving their livelihood outcomes. The paper also suggests that MNRT should ensure that local communities are at the centre of any development support program, and they (i.e. local communities) should be the ones determining development priorities and influencing the institutions involved in the processes that affect their lives.

In a nutshell, JFM and WMA models have failed to bring about the needed cooperation amongst key actors in forest and wildlife management particularly local communities and improve their livelihood outcomes. The paper, therefore, concludes that MNRT should choose and correctly implement the models which would encourage 
active cooperation amongst the key actors in forest and wildlife management particularly local communities residing around the forest and wildlife reserves.

\section{References}

Blomley, T and Ball, S (2010) Participatory Forest Management and REDD+ in Tanzania: Policy Note, World Bank, Social development, 1818 H Street, NW Washington, D.C 20433 USA

Cernea, M and Schmidt-Soltau (2006) Poverty risks and national parks: policy issues in conservation and resettlement, World Development Vol. 34 (10): pp. $1808-1830$

Goldman, M (2003) Partitioned nature, privileged knowledge: community-based conservation in Tanzania, Development and Change, Vol. 34 (5): pp. $833-862$

Globalisation and Livelihood Options of People living in Poverty (GLOPP), (2008) DFID's Sustainable Livelihoods Approach and its Framework [online] (cited 17 February 2018) Available from http://www.glopp.ch/B7/en/multimedia/B7_1_pdf2.pdf

Hamza, KFS and Kimwer, EO (2007) Tanzania’s Forest Policy and Its Practical Achievements with Respect to Community Based Forest Management in MITMIOMBO, Finnish Forest Research Institute Vol. 50: pp. 24 $-33$

Homewood, K and Rogers, WA (1991) Maasai Ecology: Pastoralists Development and Wildlife Conservation in Ngorongoro, Tanzania, Cambridge University Press

Igoe, J and Croucher, B (2007) Conservation, Commerce and Communities: The Story of Community-Based Wildlife Management Areas in Tanzania's Northern Tourist Circuit, Journal of Conservation and Society pp. $534-561$

Laltaika, E (2014) Pastoralists' Right to Land and Natural Resources in Tanzania, Oregon Review of International Law, Vol. 15 (43): pp. 43 - 62

Lokina, RB and Robinson, EJZ (2008) Determinants of Successful Participatory Forest Management in Tanzania, Environment for Development in Tanzania (EfDT), Department of Economics, University of Dar Es Salaam, Tanzania

Maganga, FP (1993) Perspectives of local resources management: Some critical issues in Babati district. Tanzania: Institutional Issues in Natural Resources Management (eds), Marcussen. H. S. Standparken, Holbaek

Ministry of Natural Resources and Tourism (MNRT), (1998a) The National Forest Policy, The Government Printer, Dar es salaam

Ministry of Natural Resources and Tourism (MNRT), (1998b) The Wildlife Policy of Tanzania, Dar es salaam, Tanzania

Ministry of Natural Resources and Tourism (MNRT), (2007) The Wildlife Policy of Tanzania, The Government Printer, Dar es salaam

Ministry of Natural Resources and Tourism (MNRT), (1998c) Ministry of Natural Resource and Tourism: Guidelines for Participatory Land Use Management in Tanzania, National Land Use Planning Commission, Dar es Salaam, Tanzania

Ministry of Natural Resources and Tourism (MNRT), (2003) Ministry of Natural Resource and Tourism: Guidelines for the Designation and Management of WMAs, Wildlife Division

Nelson, F, Nshala R and Rodgers WA (2007) The Evolution and Reform of Tanzanian Wildlife Management, Conservation and Society, Vol. 5 (2): pp. 232 - 261

Neumann, RP (1992) The Social Origins of Natural Resource Conflict in Arusha National Park, Tanzania, Ph.D. Thesis, University of California

Ostrom, E (2005) Understanding Institutional Diversity, Princeton, NJ: Princeton University Press

Potkanski, (1997) Property Concepts, Herding Patterns and Management of Natural Resources among the Ngorongoro and Salei Maasai of Tanzania, Pastoral Land Tenure Series No. 6. London: International Institute for Environment and Development

Segel, E and Heer, J (2010) Narrative Visualisation: Telling Stories with Data, Stanford University, Stanford

Shauri, V (1999) The new wildlife policy in Tanzania: Old Wine in a New Bottle? Lawyers' Environmental Action Team (LEAT): pp. 02-09

UNEP, (2002) Integrated Assessment of Trade Liberalisation and Trade - Related Policies: UNEP Country Projects - Round II; A synthesis report, United Nations, New York and Geneva

Wily, LA and Dewees PA (2001) From Users to Custodians - Changing Relations between People and the State in Forest Management in Tanzania, Policy Research Working Paper, WPS 2569, Environment and Social Development Unit, The World Bank, Dar es Salaam, Tanzania 